\title{
Titanium Dioxide Supported on Different Porous Materials as Photocatalyst for the Degradation of Methyl Green in Wastewaters
}

\author{
Haithem Bel Hadjltaief, ${ }^{1}$ Abdessalem Omri, ${ }^{1}$ Mourad Ben Zina, ${ }^{1}$ \\ Patrick Da Costa, ${ }^{2,3}$ and Maria Elena Galvez ${ }^{2,3}$ \\ ${ }^{1}$ Laboratoire Eau, Energie et Environnement (LR3E) (AD-10-02), Ecole Nationale d'Ingénieurs de Sfax, \\ Université de Sfax, BP 1173, 3038 Sfax, Tunisia \\ ${ }^{2}$ Institut Jean Le Rond d'Alembert, Université Pierre et Marie Curie (UPMC) (Paris 6), Sorbonne Universités, \\ 2 Place de la Gare de Ceinture, 78210 Saint-Cyr-l'École, France \\ ${ }^{3}$ Institut Jean Le Rond d'Alembert, UMR CNRS 7190, 2 Place de la Gare de Ceinture, 78210 Saint-Cyr-l'École, France
}

Correspondence should be addressed to Patrick Da Costa; patrick.da_costa@upmc.fr

Received 14 April 2015; Revised 3 August 2015; Accepted 3 August 2015

Academic Editor: Charles C. Sorrell

Copyright ( 2015 Haithem Bel Hadjltaief et al. This is an open access article distributed under the Creative Commons Attribution License, which permits unrestricted use, distribution, and reproduction in any medium, provided the original work is properly cited.

$\mathrm{TiO}_{2}$ nanoparticles were immobilized on two porous materials used as catalyst supports, namely, activated carbon (AC) and natural clay (NC), through an impregnation process using $\mathrm{TiO}_{2}$ (P25) as precursor. The so-prepared composite materials were characterized by X-ray diffraction (XRD), scanning electron microscopy (SEM), transition electron microscopy (TEM), and nitrogen physisorption, that is, Brunauer-Emmett-Teller (BET) surface area determination. SEM and TEM observation evidenced that $\mathrm{TiO}_{2}$ was deposited on $\mathrm{AC}$ and $\mathrm{NC}$ surface. XRD results confirmed that $\mathrm{TiO}_{2}$ existed in a mixture of anatase and rutile phases. The specific surface area of photocatalysts decreased drastically in comparison with the original materials. The photocatalytic activity of these materials was assayed in the oxidation of Methyl Green (MG) dye in aqueous medium under UV irradiation. $\mathrm{TiO}_{2} / \mathrm{AC}$ exhibited higher photocatalytic oxidation activity than $\mathrm{TiO}_{2}$ at neutral $\mathrm{pH}$. Total mineralization of $\mathrm{MG}$ was confirmed by means of COD analysis, pointing to these materials as an efficient, cost-effective, and environment friendly alternative for water treatment.

\section{Introduction}

Water pollution has become a subject of global environmental concern in recent years. Dyes from different industries such as dye synthesis, paper, printing, electroplating, food, and cosmetics are one of the major sources of water pollution [1]. Various types of dyes exist such as azo, anthraquinone, reactive, acidic, basic, neutral, disperse, and direct dyes. Azo and anthraquinone dyes are however the most commonly used ones [1-3]. Methyl Green (MG) is a basic triphenylmethane and a dicationic type dye usually used for staining of solutions in medicine and biology [4]. It is also used as a photochromophore to sensitize gelatinous film [5].
Advanced oxidation processes (AOPs) involve the generation of highly reactive radical species by several ways [6-9]. These techniques are based on the production of reactive species such as hydroxyl radicals $\left(\mathrm{HO}^{*}\right)$, which are powerful oxidizing agents and are capable of attacking a wide variety of organic molecules. AOPs photocatalysis systems include combination of semiconductors and light and semiconductor and oxidants. Heterogeneous photocatalysis is the most promising method of AOPs for toxic components in wastewater, such as phenols, herbicides, pesticides, dyes, and surfactants $[7,8]$. Titanium dioxide $\left(\mathrm{TiO}_{2}\right)$ is the most widely used photocatalyst owing to its efficiency, low cost, and chemical stability $[6,10]$. $\mathrm{TiO}_{2}$ powders such as Degussa 
P25 have been commercially available for several years. Nevertheless, after degradation tests, photocatalysts in the powder form must be removed from the suspension and this step is an important factor that may cause important problems in industrial applications $[6,11]$. To solve these problems, photocatalysts (e.g., $\mathrm{TiO}_{2}$ ) have been immobilized on various supports such as silica [12], silicon carbide [13], perlite [14], fly ash [15], zeolites [16], clay [17], and activated carbon $[10,18]$. Also, several preparation methods for $\mathrm{TiO}_{2}$ on these supports, such as hydrothermal method, sol-gel method, boil deposition, dip coating, metal organic chemical vapor deposition (MOCVD), and impregnation, have been reported $[19,20]$.

The advantages of using $\mathrm{TiO}_{2}$ supported photocatalysts were summarized as follows: (i) The support adsorbs a high amount of pollutants around the loaded $\mathrm{TiO}_{2}$. Then, the rate of photooxidation is improved [20]. (ii) The adsorbed pollutants (organic substances) are oxidized at the surface of the photocatalyst, and the resulting intermediates are also adsorbed and then further oxidized. Toxic intermediates, if formed, are not released in the air atmosphere and/or in solution phase, thus preventing secondary pollution. (iii) Since the pollutants are finally oxidized into $\mathrm{CO}_{2}$, the lifetime of the hybrid photocatalysts is long [15].

The purpose of the present work is to load $\mathrm{TiO}_{2}$ on the surface of both porous materials, that is, activated carbon (AC) and natural clay (NC), in order to prepare active and stable catalysts for the photocatalytic degradation of Methyl Green dye in wastewaters.

\section{Experimental}

2.1. Materials. The clay used in this study was sampled in Jebel Tejera-Esghira deposits located in the southeast of Tunisia from the area of Medenine. The natural clay was first purified by dispersion in water, decantation, and extraction of the fraction with a particle size smaller than $2 \mu \mathrm{m}$. Then, the natural clay was modified by sodium exchange described in our previous work $[3,21]$. Activated carbon (AC) was prepared from the physical activation of Lawsonia inermis wood, which was obtained from the field in Gabès (Tunisia). The preparation process has been described in detail elsewhere [22]. Commercial $\mathrm{TiO}_{2}$ (Degussa P25, Degussa Chemical) was used as titanium source for the preparation of photocatalysts. Methyl Green (MG, dicationic dye, chemical formula $\mathrm{C}_{27} \mathrm{H}_{35} \mathrm{Cl}_{2} \mathrm{~N}_{3} \cdot \mathrm{ZnCl}_{2}, \mathrm{MW}=608.8 \mathrm{~g} / \mathrm{mol}$, SigmaAldrich) was used to evaluate the photocatalytic efficiency of synthesized photocatalysts.

2.2. Synthesis of Photocatalytic Materials. $\mathrm{TiO}_{2} / \mathrm{AC}$ and $\mathrm{TiO}_{2} / \mathrm{NC}$ photocatalytic materials were prepared through an impregnation method. First, different weights of AC or $\mathrm{NC}$ were added under stirring to a $\mathrm{TiO}_{2}$ (P25) aqueous suspension (mixing $30 \mathrm{mg}$ of $\mathrm{TiO}_{2}$ (P25) and $100 \mathrm{~mL}$ of distilled water). After the impregnation process, the samples obtained were washed by double-distilled water, filtered, and then dried at $110^{\circ} \mathrm{C}$ for $24 \mathrm{~h}$. Finally, the dried material was calcined to $500^{\circ} \mathrm{C}$ for $3 \mathrm{~h}$ in a nitrogen-purged reactor tube

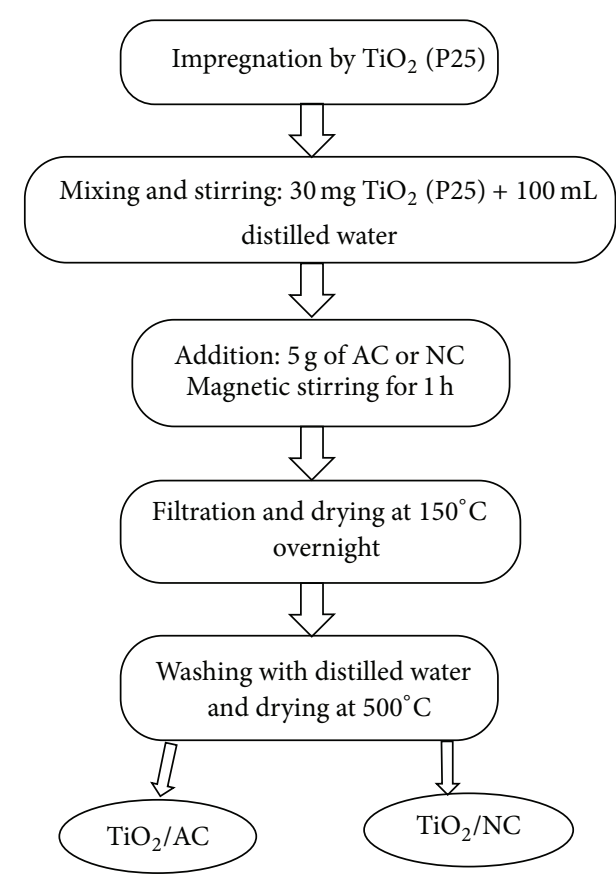

FIGURE 1: Scheme of the preparation method of photocatalysts by the impregnation method.

with a heating rate of $5^{\circ} \mathrm{C} / \mathrm{min}$. The steps of the photocatalysts preparation are presented in Figure 1.

2.3. Characterization of Photocatalysts. Several techniques were employed for the characterization of the samples. Samples were also examined under a scanning electron microscope (SEM, Hitachi SU-70). The structural feature of these samples was observed at the accelerated voltage of $1.0 \mathrm{kV}$. High resolution transmission electron microscopy (HRTEM) images were thus acquired (JEOL JEM 2011) equipped with LaB6 filament and operating at $200 \mathrm{kV}$. The images were collected with a $4008 \times 2672$ pixels' CCD camera (Gatan Orius SC1000) coupled with the Digital Micrograph software. Chemical analyses were obtained by an EDX microanalyzer (PGT IMIX PC) mounted on the microscope. The catalysts were dispersed in ethanol and sonicated. A drop of the dispersion was deposited on a carbon-coated copper grid for the TEM observations.

Nitrogen adsorption-desorption isotherms were measured at $-196^{\circ} \mathrm{C}$ (Fisons Sorptomatic 1990) after outgassing $\left(10^{-5} \mathrm{~Pa}\right)$ for $24 \mathrm{~h}$ at ambient temperature. The specific surface area, $S_{\mathrm{BET}}$, was determined according to the BrunauerEmmett-Teller (BET) method at the relative pressure, $p / p_{0}$, in the range of $0.05-0.1$.

The porosity of the photocatalysts was measured by pycnometry. In order to determine the real density $\left(\rho_{s}\right)$, water was chosen since it can penetrate pores [23], whereas, for the apparent density $\left(\rho_{p}\right)$, mercury was chosen since it does not penetrate into the porous network. The porosity $(P)$ can be calculated by the following equation:

$$
P=\frac{\rho_{s}-\rho_{p}}{\rho_{s}} \times 100 \% .
$$


For the crystal phase composition and the crystallite size of the photocatalysts, X-ray diffraction measurements were carried out at room temperature using an X-ray diffractometer (Philips PW 1710 diffractometer) $(\mathrm{Cu} \mathrm{K} \alpha, 40 \mathrm{kV} / 40 \mathrm{~mA}$, scanning rate of $2 \Theta$ per $\mathrm{min})$. The crystallite size was calculated by X-ray line-broadening analysis using Scherrer equation $[17,19]$.

2.4. Photoreactor and Photodegradation Procedure. Photocatalytic oxidation experiments were performed in an open Pyrex-glass cell with $250 \mathrm{~mL}$ capacity ( of $5 \mathrm{~cm}$ inside diameter and $11 \mathrm{~cm}$ height). The design description of photocatalytic reactor was reported in our earlier study [3]. Irradiation was carried out using an UV-lamp (Black-Ray B 100 W UV-lamp, $\mathrm{V}-100 \mathrm{AP}$ series) with a wavelength of $365 \mathrm{~nm}$.

A suspension was prepared by adding appropriate amount of support $\mathrm{TiO}_{2} / \mathrm{AC}$ or $\mathrm{TiO}_{2} / \mathrm{NC}$ to $200 \mathrm{~mL}$ of $\mathrm{MG}$ aqueous solution $(75 \mathrm{mg} / \mathrm{L})$ at $\mathrm{pH}$. The $\mathrm{pH}$ of suspension was measured using $\mathrm{PH}-035$ digital $\mathrm{pH}$ meter from Changlilai Technology Co., Ltd. (Shenzhen, China), by adding $\mathrm{H}_{2} \mathrm{SO}_{4}(0.1 \mathrm{~mol} / \mathrm{L})$ or $\mathrm{NaOH}(0.1 \mathrm{~mol} / \mathrm{L})$. All the experiments were performed at an ambient temperature $(25 \pm$ $1^{\circ} \mathrm{C}$ ) and atmospheric pressure. During the experiment, air was continuously bubbled into the catalyst suspension. Prior to irradiation, the suspension was magnetically stirred in the dark for at least $60 \mathrm{~min}$ to ensure the establishment of an adsorption/desorption equilibrium. The experimental work of this study involved several parameters such as the $\mathrm{pH}$, catalyst loading, initial dye concentration, and $\mathrm{H}_{2} \mathrm{O}_{2}$ concentration. Firstly, for examining the effect of $\mathrm{pH}$, the $\mathrm{pH}$ of $\mathrm{MG}$ solution was adjusted using $0.1 \mathrm{HCl}$ and 0.1 $\mathrm{NaOH}$ aqueous solutions to be 3 to 11, while fixing the MG concentration at $75 \mathrm{mg} / \mathrm{L}$ and the dosages at $1 \mathrm{~g} / \mathrm{L}$ of the photocatalysts. Catalyst concentration was chosen from 0.25 to $1.75 \mathrm{~g} / \mathrm{L}$, for $75 \mathrm{mg} / \mathrm{L}$ of $\mathrm{MG}$ solution, at $\mathrm{pH}=7$. The influence of the MG dye concentration was also evaluated by varying its concentration range from $25 \mathrm{mg} / \mathrm{L}$ to $150 \mathrm{mg} / \mathrm{L}$, at a fixed $\mathrm{pH}$ of 7 in the presence of $0.75 \mathrm{~g} / \mathrm{L}$. Finally, the influence of the $\mathrm{H}_{2} \mathrm{O}_{2}$ amount added to the MG solution was evaluated by both dosages $8 \mathrm{~mL}$ and $16 \mathrm{~mL}\left(1000 \mathrm{mg} \mathrm{L}^{-1}\right.$ of $\mathrm{H}_{2} \mathrm{O}_{2}$ solution, prepared from $\mathrm{H}_{2} \mathrm{O}_{2}$ (30\%) Merck reagent), at a fixed $\mathrm{pH}$ of 7 and $\mathrm{MG}$ concentration of $75 \mathrm{mg} / \mathrm{L}$, in the presence of $0.75 \mathrm{~g} / \mathrm{L}$.

During reaction, about $4 \mathrm{~mL}$ of aliquots was sampled and separated by filtration using PTFE filters $(0.45 \mu \mathrm{m})$ to determine the residual MG concentration using UV-Vis spectrophotometer (Shimadzu 2450, Japan) at the maximal adsorption wavelength of MG $\lambda_{\max }=631 \mathrm{~nm}$. Chemical Oxygen Demand (COD) was determined using the reactor digestion method based on the method of acidic oxidation by bichromate [24].

Discoloration efficiency and mineralization efficiency were calculated as follows:

$$
\chi=\left(\frac{C_{0}-C_{t}}{C_{0}}\right) \times 100(\%),
$$

where $C_{t}$ and $C_{0}$ denote the time-dependent concentration/COD and the initial concentration/COD, respectively.
TABLE 1: Textural and structural properties of the samples.

\begin{tabular}{lcccc}
\hline & \multicolumn{3}{c}{$\begin{array}{c}\text { Sample } \\
\mathrm{TiO}_{2} / \mathrm{NC}\end{array}$} & $\mathrm{TiO}_{2} / \mathrm{AC}$ \\
\hline$V_{p}\left(\mathrm{~cm}^{3} / \mathrm{g}\right)$ & 0,2 & 0.441 & 0,107 & 0.286 \\
$P(\%)$ & 19 & 45.6 & 10.05 & 37.11 \\
$S_{\mathrm{BET}}\left(\mathrm{m}^{2} / \mathrm{g}\right)$ & 64 & 584 & 49.11 & 420 \\
Crystallite size, $D(\mathrm{~nm})$ & - & - & 18.5 & $21.8 \mathrm{~nm}$ \\
Anatase content, $A(\%)$ & - & - & 94 & 89 \\
$\mathrm{TiO}_{2}$ (wt.\%) & - & - & 19.1 & 23.7 \\
\hline
\end{tabular}

\section{Results and Discussion}

3.1. Characterization of the Prepared Photocatalysts. The structure and morphology of the catalyst are very important parameters since they strongly determine its photocatalytic behavior. SEM images of NC and AC before and after deposition of $\mathrm{TiO}_{2}$ are shown in Figure 2. From the micrograph, it is clear that the surface morphologies of NC (Figure 2(a)) and AC (Figure 2(b)) have a porous nature with uniform structures. After impregnation process, the $\mathrm{TiO}_{2}$ particles are found to be well-dispersed. However, the immobilization of $\mathrm{TiO}_{2}$ in both supports partially blocks the porosity. TEM images also confirm that $\mathrm{TiO}_{2}$ was successfully loaded onto the surface of $\mathrm{NC}$ and $\mathrm{AC}$ at an average particle size of about $10 \mathrm{~nm}$. The presence of $\mathrm{TiO}_{2}$ in the prepared materials was confirmed by EDX analysis (Table 1 ). $\mathrm{TiO}_{2} / \mathrm{AC}$ evidences the highest $\mathrm{TiO}_{2}$ concentration of 23.7 wt.\%.

The BET surface and pore volume of the prepared samples are presented in Table 1 . The large decrease in the surface area, total pore volume, and porosity of $\mathrm{TiO}_{2} / \mathrm{NC}$ and $\mathrm{TiO}_{2} / \mathrm{AC}$ indicates that the pores of $\mathrm{AC}$ or $\mathrm{NC}$ are remarkably blocked by the loaded $\mathrm{TiO}_{2}$. The presence of an anatase phase for $\mathrm{TiO}_{2}$ can further contribute to this reduction in the surface area and pore volumes due to its presence within the micro-meso texture. Thus, the percentage of anatase can be considered to be proportional to the reduction in surface area and pore volume. Thus, this parameter may be used as an inverse indicator of the loss of surface area and porosity in these materials.

The X-ray diffraction (XRD) pattern of pure $\mathrm{TiO}_{2}(\mathrm{P} 25)$, $\mathrm{TiO}_{2} / \mathrm{AC}$, and $\mathrm{TiO}_{2} / \mathrm{NC}$ is shown in Figure 3. The XRD diffraction patterns for the natural clay evidenced quartz, kaolinite, and illite coexisting as the main crystalline phases $[17,21]$. The XRD for the activated carbon evidences two wide diffraction peaks typical of graphitic structures in activated carbon [22]. Upon $\mathrm{TiO}_{2}$ loading, the XRD patterns of $\mathrm{TiO}_{2} / \mathrm{NC}$ and $\mathrm{TiO}_{2} / \mathrm{AC}$ photocatalysts show the appearance of peaks at $2 \theta$ values of $25.281^{\circ}, 37.934^{\circ}, 48.376^{\circ}, 55.296^{\circ}$, and $62.728^{\circ}$ corresponding to the (101), (103), (200), (105), and (213) planes of anatase $\mathrm{TiO}_{2}$ [18], JCPDS number 21-1272. The peaks at $2 \theta$ values of $27.4^{\circ}$ and $36.1^{\circ}$ are characteristic of rutile $\mathrm{TiO}_{2}$, JCPDS number 21-1276. The crystallization of amorphous $\mathrm{TiO}_{2}$ into anatase occurs at about $380^{\circ} \mathrm{C}$ [25]. The transformation of anatase into rutile takes place between $550^{\circ} \mathrm{C}$ and $650^{\circ} \mathrm{C}$ [25]. This is the reason why, upon calcination at $500^{\circ} \mathrm{C}$ for $3 \mathrm{~h}$, the rutile phase appears in 


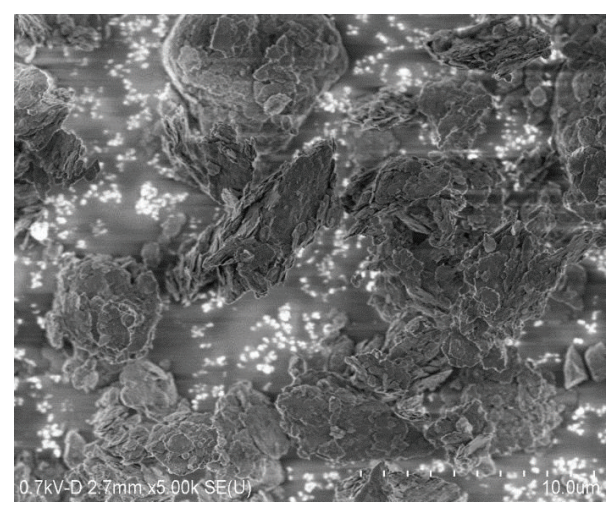

(a)

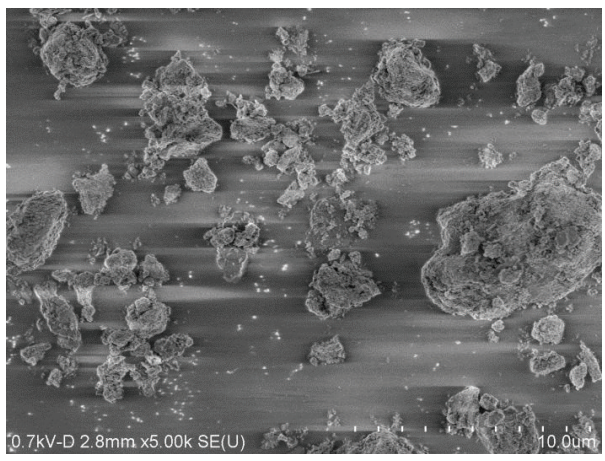

(c)

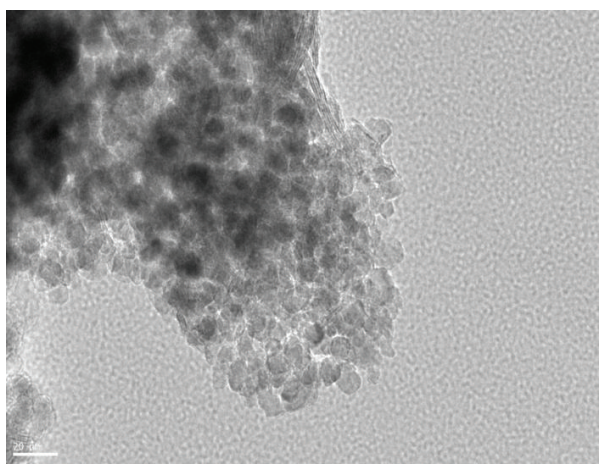

(e)

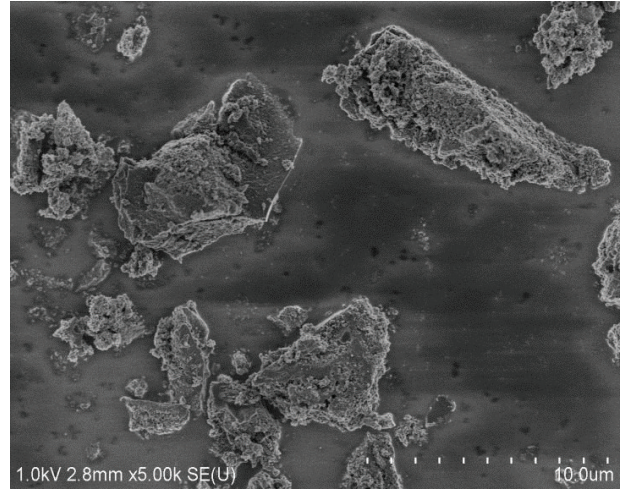

(b)

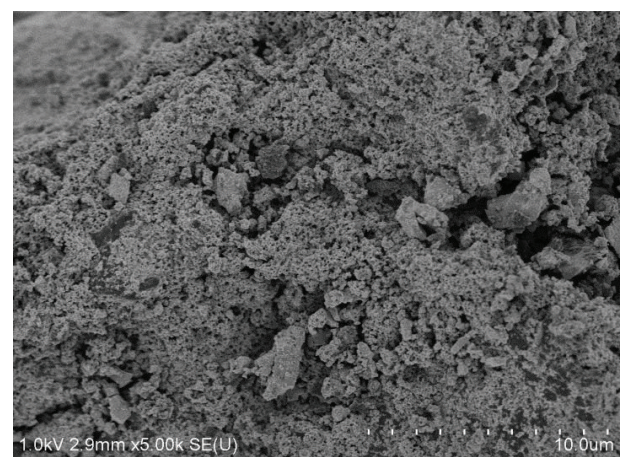

(d)

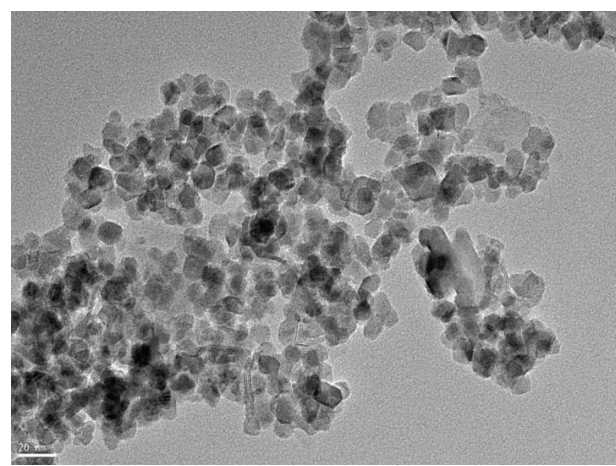

(f)

Figure 2: SEM images of (a) NC, (b) AC, (c) $\mathrm{TiO}_{2} / \mathrm{NC}$, and (d) $\mathrm{TiO}_{2} / \mathrm{AC}$ and TEM images of (e) $\mathrm{TiO}_{2} / \mathrm{NC}$ and (f) $\mathrm{TiO}_{2} / \mathrm{AC}$.

$\mathrm{TiO}_{2} / \mathrm{AC}$ and $\mathrm{TiO}_{2} / \mathrm{NC}$ materials. As listed in Table 1 , the relative contents of anatase and rutile are estimated using the Spurr-Myers equation [26]:

$$
A(\%)=\frac{I_{A}}{I_{A}+1.265 \times I_{R}} \times 100,
$$

where $A(\%)$ is the relative content of anatase and $I_{A}$ and $I_{R}$ are the intensities of the anatase (101) peak at $2 \theta=25.281^{\circ}$ and the rutile (101) peak at $2 \theta=27.234^{\circ}$. The anatase content of materials is $94 \%$ and $89 \%$ for $\mathrm{TiO}_{2} / \mathrm{AC}$ and $\mathrm{TiO}_{2} / \mathrm{NC}$, respectively. These values show that the anatase phase is highly predominant in all cases. The main active crystal phases of $\mathrm{TiO}_{2}$ are anatase and rutile. Out of the two $\mathrm{TiO}_{2}$ phases, anatase is typically more active in photocatalytic reactions
[18, 19]. According to Ambrus et al. [27], photocatalysts containing the anatase phase are more active than rutile-only catalyst.

The $\mathrm{TiO}_{2}$ crystal sizes in $\mathrm{TiO}_{2} / \mathrm{NC}$ and $\mathrm{TiO}_{2} / \mathrm{AC}$ materials were calculated using Scherrer's equation through the XRD line-broadening method:

$$
D=\frac{k \lambda}{\beta \cos (\theta)} .
$$

In this equation, $D$ is the crystallite size of the photocatalyst, $k$ is dimensionless constant (0.9), $\lambda$ is the wavelength of $\mathrm{X}$ ray $(\mathrm{Cu} \mathrm{K} \alpha$ radiation $\lambda=1.5406 \AA), \beta$ is the full width at half-maximum (FWHM) of the diffraction peak, and $\theta$ is the diffraction angle. The average crystallite size for $\mathrm{TiO}_{2} / \mathrm{NC}$ was 


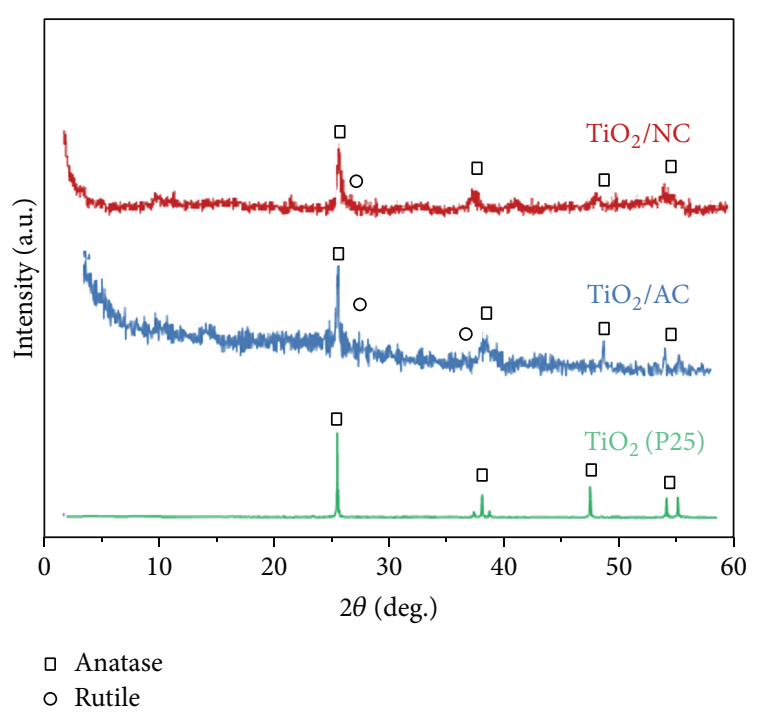

FIgure 3: XRD patterns of $\mathrm{TiO}_{2} / \mathrm{NC}, \mathrm{TiO}_{2} / \mathrm{NC}$, and $\mathrm{TiO}_{2}(\mathrm{P} 25)$.

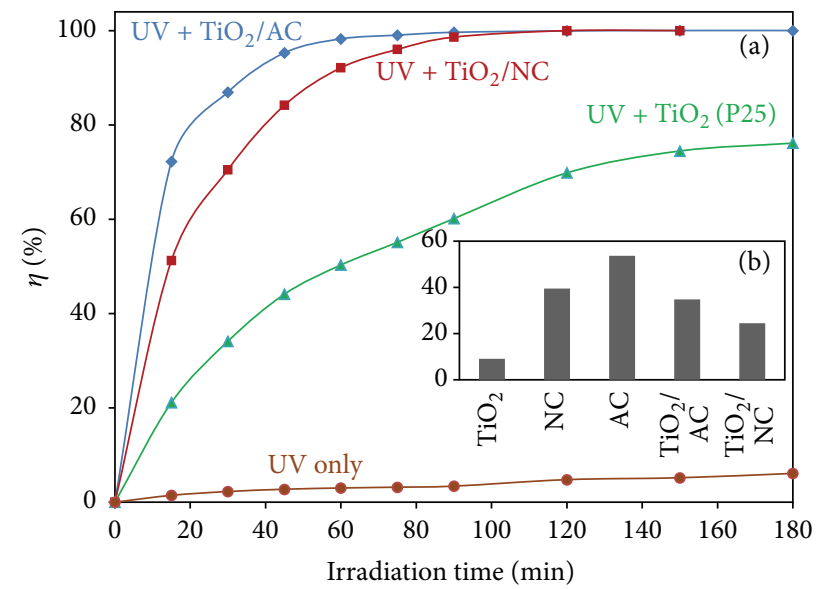

FIgURE 4: Photocatalytic degradation of $\mathrm{MG}$ by the different samples. The inset shows the maximum adsorption in the dark after 60 minutes (initial concentration of $\mathrm{MG}=75 \mathrm{mg} / \mathrm{L}$, photocatalyst amount $=1 \mathrm{~g} / \mathrm{L}$, and irradiation time $=180 \mathrm{~min}$ ).

found to be $18.5 \mathrm{~nm}$, whereas a crystallite size of $21.8 \mathrm{~nm}$ was estimated for $\mathrm{TiO}_{2} / \mathrm{AC}$.

\subsection{Photocatalytic Degradation of Methyl Green. Figure 4} shows the results of the photocatalytic experiments in the presence of the different materials prepared and under different reaction conditions. The photolysis of MG under UV irradiation, without the presence of photocatalysts, results in negligible degradation of the dye, at least during the 180 min duration of the test. Regarding the direct adsorption of MG on the surface of the photocatalysts (tests in the absence of UV irradiation), the amount of MG adsorbed onto $\mathrm{TiO}_{2} / \mathrm{AC}$ irradiation was found to be higher than for $\mathrm{TiO}_{2} / \mathrm{NC}$. This fact can be assigned to the larger surface area of this material and to the well-known good adsorption properties of activated carbon. For the sake of comparison, the nonimpregnated supports were tested in the photocatalytic degradation of MG: $53.7 \%$ and $39.5 \%$ of the dye were, respectively, removed by the activated carbon and natural clay from $100 \mathrm{mg} / \mathrm{L}$ MG solutions after 60 minutes of reaction. These percentages of MG degradation can be only related to enhanced absorption of the organic dye on the support surface. The incorporation of $\mathrm{TiO}_{2}$ results in extensive pore blockage and in a considerable reduction of the adsorption capacity. $\mathrm{TiO}_{2}$ supported on activated carbon or on natural clay is more active than pure $\mathrm{TiO}_{2}$ (P25) powder. It can be seen that the removal of MG using pure $\mathrm{TiO}_{2}$ (P25) reached $52.8 \%$ within 60 min irradiation time. In the presence of $\mathrm{TiO}_{2} / \mathrm{AC}$ and $\mathrm{TiO}_{2} / \mathrm{NC}, \mathrm{MG}$ degradation reached $98.6 \%$ and $90.2 \%$, within the same irradiation time. Note that the photocatalytic activity of $\mathrm{TiO}_{2} / \mathrm{AC}$ is higher than that of $\mathrm{TiO}_{2} / \mathrm{NC}$. This result is in correlation with the physicochemical properties of materials; the anatase content and the specific surface area of $\mathrm{TiO}_{2} / \mathrm{AC}$ were higher than those of $\mathrm{TiO}_{2} / \mathrm{NC}$ (Table 1). Moreover, better light absorption properties of a "black" material such as activated carbon can be expected.

It has been established that photocatalyzed degradation of organic pollutants in aqueous solution is initiated by the photoexcitation of $\mathrm{TiO}_{2}$, followed by the formation of an electron-hole pair on the surface of catalyst $[7,18,19]$ :

$$
\mathrm{TiO}_{2}+h v \longrightarrow \mathrm{TiO}_{2}+\mathrm{h}^{+}{ }_{v b}+\mathrm{e}^{-}{ }_{c b}
$$

The high oxidation potential of the hole $\left(\mathrm{h}^{+}{ }_{v b}\right)$ allows the oxidation of organic pollutant (dye) to the degradation products:

$$
\begin{aligned}
\mathrm{h}^{+}{ }_{v b}+\text { pollutant } & \longrightarrow \text { pollutant }^{*+} \\
& \longrightarrow \text { degradation of pollutant }
\end{aligned}
$$

However, very reactive hydroxyl radicals $\left({ }^{\circ} \mathrm{OH}\right)$ can also be formed either by the decomposition of water or by the reaction of the hole with $\mathrm{OH}^{-}$:

$$
\begin{aligned}
& \mathrm{h}^{+}{ }_{v b}+\mathrm{H}_{2} \mathrm{O} \longrightarrow \mathrm{HO}^{\circ}+\mathrm{H}^{+} \\
& \mathrm{h}^{+}{ }_{v b}+\mathrm{HO}^{-} \longrightarrow \mathrm{HO}^{\circ}
\end{aligned}
$$

$\cdot \mathrm{OH}$ is an exclusively strong, nonselective oxidant, which conducts the partial or complete mineralization of organic pollutants $[7,8]$.

Electrons $\left(\mathrm{e}^{-}{ }_{c b}\right)$ in the conduction bond on the $\mathrm{TiO}_{2}$ surface can reduce molecular oxygen to superoxide anions. These superoxide anions are responsible for the generation of ${ }^{\circ} \mathrm{OH}$ that has been indicated as the primary source of pollutant degradation [19]:

$$
\begin{aligned}
& \mathrm{e}_{c b}^{-}+\mathrm{O}_{2} \longrightarrow \mathrm{O}_{2}^{\cdot-} \\
& 2 \mathrm{O}_{2}^{\cdot-}+2 \mathrm{H}_{2} \mathrm{O} \longrightarrow \mathrm{HO}^{\bullet}+2 \mathrm{HO}^{-}+\mathrm{O}_{2} \\
& \mathrm{HO}+\text { pollutant (MG) } \\
& \quad \longrightarrow \mathrm{CO}_{2}+\mathrm{H}_{2} \mathrm{O}+\text { other degradation products }
\end{aligned}
$$




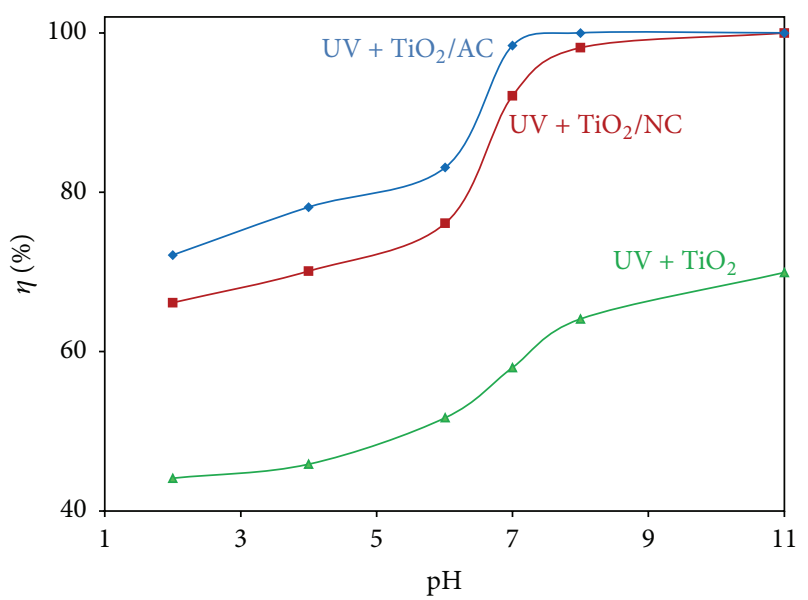

FIGURE 5: Effect of $\mathrm{pH}$ on photocatalytic degradation of $\mathrm{MG}$ using $\mathrm{TiO}_{2}(\mathrm{P} 25), \mathrm{TiO}_{2} / \mathrm{NC}$, and $\mathrm{TiO}_{2} / \mathrm{AC}$ (initial concentration of $\mathrm{MG}=75 \mathrm{mg} / \mathrm{L}$, photocatalyst amount $=0.75 \mathrm{~g} / \mathrm{L}$, and irradiation time $=180 \mathrm{~min}$ ).

3.3. Effect of $p H$. Wastewaters from textile industries usually have a wide range of $\mathrm{pH}$. Thus, $\mathrm{pH}$ plays an important role in photodegradation processes $[4,8,28]$. The effect of the initial solution $\mathrm{pH}$ on the photocatalytic degradation in the presence of $\mathrm{TiO}_{2}$ supported on $\mathrm{AC}$ and NC is presented in Figure 5. MG removal increases with increasing initial $\mathrm{pH}$ of the dye solution. The influence of $\mathrm{pH}$ on photocatalytic activity has been related to the surface charge properties of the photocatalysts and could be explained based on the point of zero charge (pzc). The point of zero charge (pzc) of $\mathrm{TiO}_{2}$ is 6.8 [28]. In acidic media $(\mathrm{pH}<6.8)$, the surface of $\mathrm{TiO}_{2}$ is positively charged, whereas it is negatively charged under alkaline conditions $(\mathrm{pH}>6.8)$ according to

$$
\begin{gathered}
\mathrm{TiOH}+\mathrm{H}^{+} \longleftrightarrow \mathrm{TiOH}_{2}^{+} \quad \text { at } \mathrm{pH}<\mathrm{pzc} \\
\mathrm{TiOH}+\mathrm{OH}^{-} \longleftrightarrow \mathrm{TiO}^{-}+\mathrm{H}_{2} \mathrm{O} \quad \text { at } \mathrm{pH}>\mathrm{pzc}
\end{gathered}
$$

Methyl Green, a cationic dye, is positivity charged due to the ammonium groups which are ionized in water; their electrostatic attraction to the catalyst surface is favorable in basic solution and hindered in acidic media, due to the columbic repulsion between the positively charged photocatalyst surface and the positively charged dye molecules $[4,28$, 29]. Thus, interaction and thus reaction might be favored at high $\mathrm{pH}$. Moreover, the generation of $\mathrm{HO}^{\circ}$ radicals by the effect of UV irradiation may also be responsible for increasing reaction rate in a basic environment. In acidic media $(\mathrm{pH}<$ 7 ), such radical species are rapidly scavenged and therefore the reaction rate decreases, thus resulting in favored reaction at high $\mathrm{pH}$.

3.4. Effect of Catalytic Concentration. In order to avoid the use of excess catalyst, it is necessary to find out the optimum loading for efficient removal of the organic compounds in wastewaters. Several authors have investigated the reaction rate as a function of catalyst loading in photocatalytic degradation process [10,29-31]. The effect of catalyst concentration

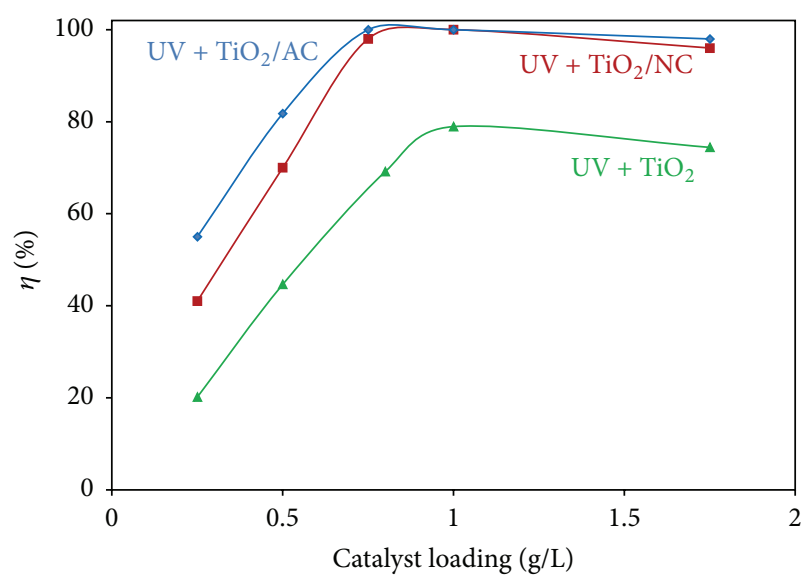

FIGURE 6: Effect of catalyst loading on photocatalytic degradation of MG using $\mathrm{TiO}_{2}(\mathrm{P} 25), \mathrm{TiO}_{2} / \mathrm{NC}$, and $\mathrm{TiO}_{2} / \mathrm{AC}$ (initial concentration of $\mathrm{MG}=75 \mathrm{mg} / \mathrm{L}$ and irradiation time $=180 \mathrm{~min}$ at $\mathrm{pH}=7)$.

on degradation of the $\mathrm{MG}$ dye over $\mathrm{TiO}_{2}, \mathrm{TiO}_{2} / \mathrm{NC}$, and $\mathrm{TiO}_{2} / \mathrm{AC}$ is shown in Figure 6. The catalyst loading changed from 0.25 to $1.75 \mathrm{~g} / \mathrm{L}$. The figure shows that the percentage of removal of $\mathrm{MG}$ is enhanced when the amount of catalyst in the reactor increases up to $1 \mathrm{~g} / \mathrm{L}$ over $\mathrm{TiO}_{2}$ (P25) and up to $0.75 \mathrm{~g} / \mathrm{L}$ over both $\mathrm{TiO}_{2} / \mathrm{NC}$ and $\mathrm{TiO}_{2} / \mathrm{AC}$ and then decreases for higher catalyst loads. This increase in the degradation efficiency in the presence of an increased amount of catalyst in the solution is obviously due to the increase of the active material and thus $\mathrm{TiO}_{2}$ active sites, resulting in enhanced free hydroxyl radical generation [29-31]. However, for catalyst loads higher than $1 \mathrm{~g} / \mathrm{L}$, a steady state is reached in terms of degradation since a plateau is reached considering the experimental errors.

3.5. Effect of Initial Dye Concentration. Dye concentration was varied between 25 and $150 \mathrm{mg} / \mathrm{L}$ with constant catalyst loading at $\mathrm{pH}$ 7. The influence of initial dye concentration is shown in Figures $7(\mathrm{a}), 7(\mathrm{~b})$, and $7(\mathrm{c})$, in the presence of $\mathrm{TiO}_{2}(\mathrm{P} 25), \mathrm{TiO}_{2} / \mathrm{NC}$, and $\mathrm{TiO}_{2} / \mathrm{AC}$, respectively, where a plot of $\ln \left(C / C_{0}\right)$ versus time of irradiation is represented. From the results, the photocatalytic degradation of $\mathrm{MG}$ followed pseudo-first-order kinetics (Table 2). A linear relation between dye concentration and irradiation time has been observed. It was found that the increase in the dye concentration decreases the removal rate. The results are listed in Table 2. One can conclude that $\mathrm{TiO}_{2} / \mathrm{AC}$ catalyst is more efficient than $\mathrm{TiO}_{2} / \mathrm{NC}$, with the ratio of apparent rate varying from 1.2 to 1.6 depending on the conditions.

Similar results have been reported for the photocatalytic oxidation of other dyes $[1,17,30]$. The rate of degradation relates to the rate of ${ }^{\circ} \mathrm{OH}$ radicals formation and to the probability of ${ }^{\bullet} \mathrm{OH}$ radicals to react with the dye molecules. Since the generation of radicals remains constant for each set of reaction conditions, the probability of dye molecule to react with hydroxyl radical decreases as dye concentration decreases, resulting in lower reaction rate. However, at relatively high initial dye concentrations, the path length of 
TABLE 2: Degradation reaction rate constants by UV irradiation photocatalytic oxidation of $\mathrm{MG}$ dye over $\mathrm{TiO}_{2} / \mathrm{AC} \mathrm{TiO} / \mathrm{NC}_{2}$ and TiO $2(\mathrm{P} 25)$.

\begin{tabular}{|c|c|c|c|c|c|c|}
\hline \multirow{2}{*}{ Initial concentration $(\mathrm{mg} / \mathrm{L})$} & \multicolumn{2}{|c|}{$\mathrm{TiO}_{2} / \mathrm{AC}$} & \multicolumn{2}{|c|}{$\mathrm{TiO}_{2} / \mathrm{NC}$} & \multicolumn{2}{|c|}{$\mathrm{TiO}_{2}(\mathrm{P} 25)$} \\
\hline & $k^{\prime}$ & $R^{2}$ & $k^{\prime}$ & $R^{2}$ & $k^{\prime}$ & $R^{2}$ \\
\hline 25 & 0,0458 & 0,9942 & 0,0306 & 0,9945 & 0,0214 & 0,9944 \\
\hline 50 & 0,0384 & 0,994 & 0,0239 & 0,9898 & 0,0195 & 0,9917 \\
\hline 75 & 0,0303 & 0,987 & 0,0187 & 0,9941 & 0,0146 & 0,9828 \\
\hline 100 & 0,0253 & 0,9934 & 0,0139 & 0,9915 & 0,0091 & 0,9904 \\
\hline 150 & 0,0133 & 0,9883 & 0,0106 & 0,9869 & 0,0043 & 0,9564 \\
\hline
\end{tabular}

$k^{\prime}$ : estimated rate constant; $R^{2}$ : correlation factor.

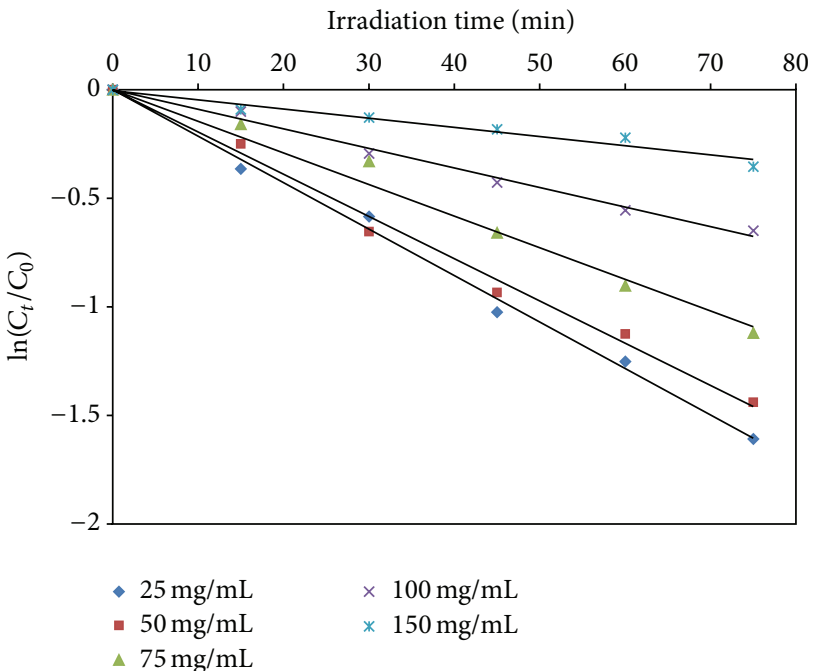

(a)

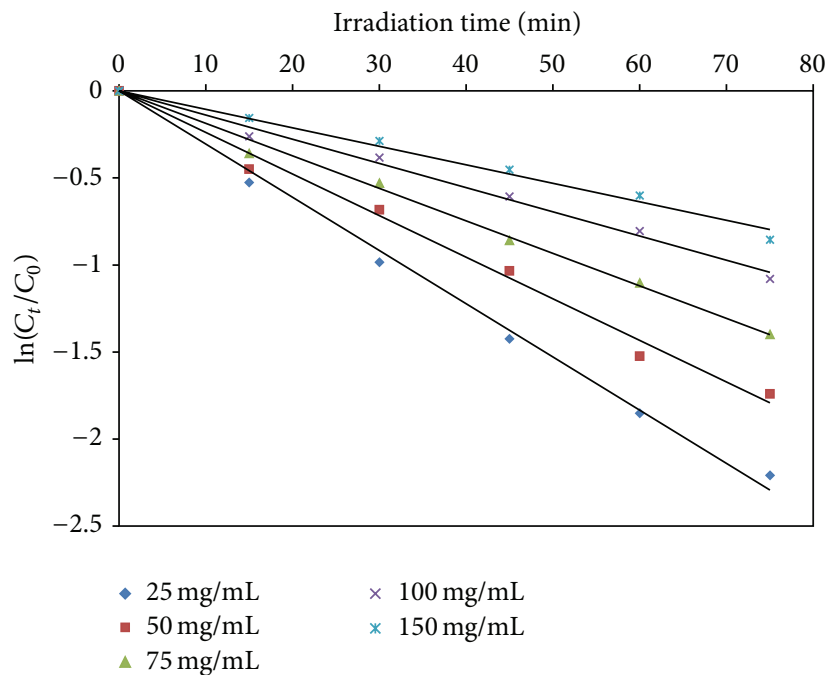

(b)

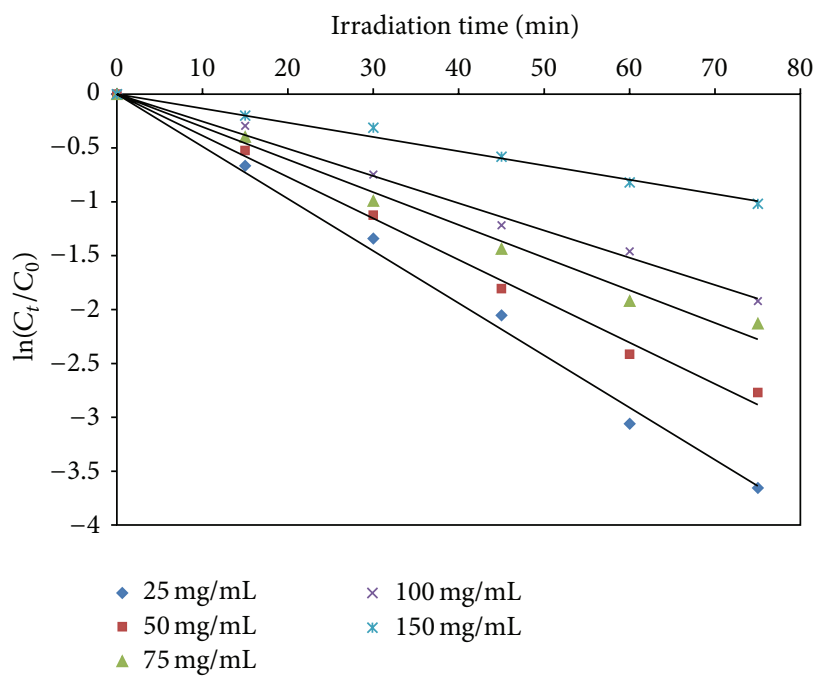

(c)

Figure 7: (a) Effect of initial dye concentration on photocatalytic degradation of $\mathrm{MG}$ using $\mathrm{TiO}_{2}(\mathrm{P} 25)$ (photocatalyst amount $=0.75 \mathrm{~g} / \mathrm{L}$ and irradiation time $=180 \mathrm{~min}$ at $\mathrm{pH}=7$ ). (b) Effect of initial dye concentration on photocatalytic degradation of $\mathrm{MG}$ using $\mathrm{TiO}_{2} / \mathrm{NC}$ (photocatalyst amount $=0.75 \mathrm{~g} / \mathrm{L}$ and irradiation time $=180 \mathrm{~min}$ at $\mathrm{pH}=7$ ). 


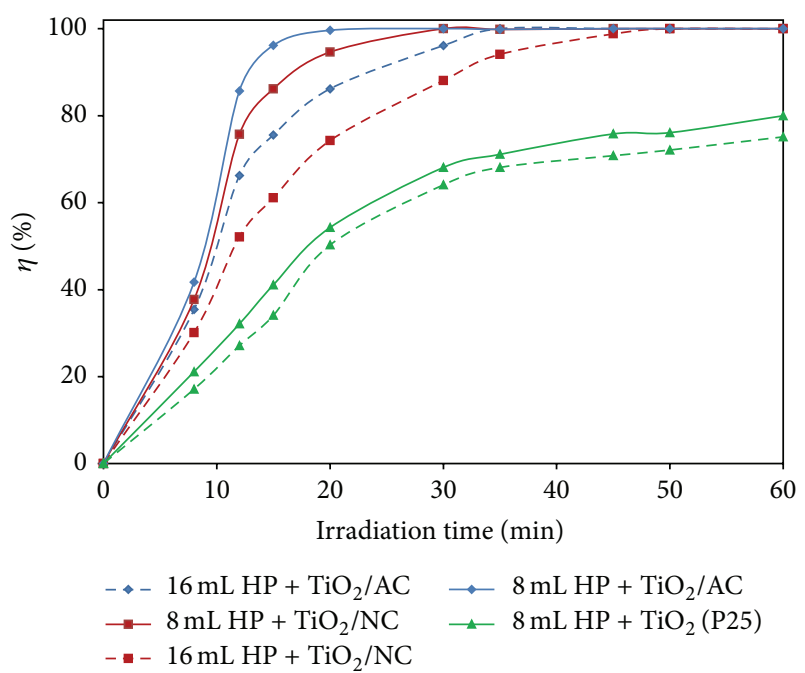

FIGURE 8: Effect of HP concentration on photocatalytic degradation of MG using $\mathrm{TiO}_{2}$ (P25), $\mathrm{TiO}_{2} / \mathrm{NC}$, and $\mathrm{TiO}_{2} / \mathrm{AC}$ (initial concentration of $\mathrm{MG}=75 \mathrm{mg} / \mathrm{L}$, photocatalyst amount $=0.75 \mathrm{~g} / \mathrm{L}$, and irradiation time $=30 \mathrm{~min}$ at $\mathrm{pH}=7$ ).

the photons entering the solution also decreases. Thus, the photocatalytic degradation efficiency decreases within the range of very high dye concentrations $[16,30,32]$.

3.6. Effect of Addition of $\mathrm{H}_{2} \mathrm{O}_{2}$. Addition of Hydrogen Peroxide (HP) to $\mathrm{TiO}_{2}$ suspensions is a well-known strategy towards increasing the degradation efficiency of organic pollutants in wastewaters $[7,8,32,33] . \mathrm{H}_{2} \mathrm{O}_{2}$ is considered to have two functions in the photocatalytic oxidation. It accepts a photogenerated electron from the conduction band of the semiconductor to form ${ }^{\circ} \mathrm{OH}$ radical (reaction (14)), and, in addition, it forms ${ }^{\circ} \mathrm{OH}$ radicals according to reaction (15) [8]:

$$
\begin{gathered}
\mathrm{H}_{2} \mathrm{O}_{2}+\mathrm{e}^{-} \longrightarrow \mathrm{HO}^{\bullet}+\mathrm{OH}^{-} \\
\mathrm{H}_{2} \mathrm{O}_{2}+\mathrm{O}_{2}^{\cdot-} \longrightarrow \mathrm{HO}^{\bullet}+\mathrm{OH}^{-}+\mathrm{O}_{2}
\end{gathered}
$$

Figure 8 shows the results of the photodegradation experiments carried out at both $\mathrm{H}_{2} \mathrm{O}_{2}$ dosages $8 \mathrm{~mL}$ and $16 \mathrm{~mL}$, at $\mathrm{pH}=7$, in the presence of $0.75 \mathrm{~g} / \mathrm{L}$ photocatalysis and UV irradiation. Results point out an optimal oxidant dosage. Excess of $\mathrm{H}_{2} \mathrm{O}_{2}$ can act in fact as ${ }^{\circ} \mathrm{OH}$ scavenger resulting in the generation of perhydroxyl radical $\left(\mathrm{HO}_{2}{ }^{*}\right)$ (see (16)-(18)), a less strong oxidant as compared to hydroxyl radicals $[3,8]$ :

$$
\begin{gathered}
\mathrm{H}_{2} \mathrm{O}_{2}+\mathrm{HO}^{\bullet} \longrightarrow \mathrm{HO}_{2}^{\cdot}+\mathrm{H}_{2} \mathrm{O} \\
\mathrm{HO}^{\bullet}+\mathrm{HO}_{2}^{\cdot} \longrightarrow \mathrm{O}_{2}+\mathrm{H}_{2} \mathrm{O} \\
\mathrm{H}_{2} \mathrm{O}_{2}+\mathrm{h}^{+} \longrightarrow \mathrm{H}^{+}+\mathrm{HO}_{2}{ }^{\circ}
\end{gathered}
$$

3.7. UV-Visible Absorption and COD Analysis. Mineralization of MG (complete oxidation) in the presence of the different photocatalytic materials has been evaluated by means of following the evolution of UV-Vis absorption and by means of COD measurements. Degradation experiments were performed at $\mathrm{pH}$ of $6.51,75 \mathrm{mg} / \mathrm{L}$ dye concentration, $100 \mathrm{mg}$

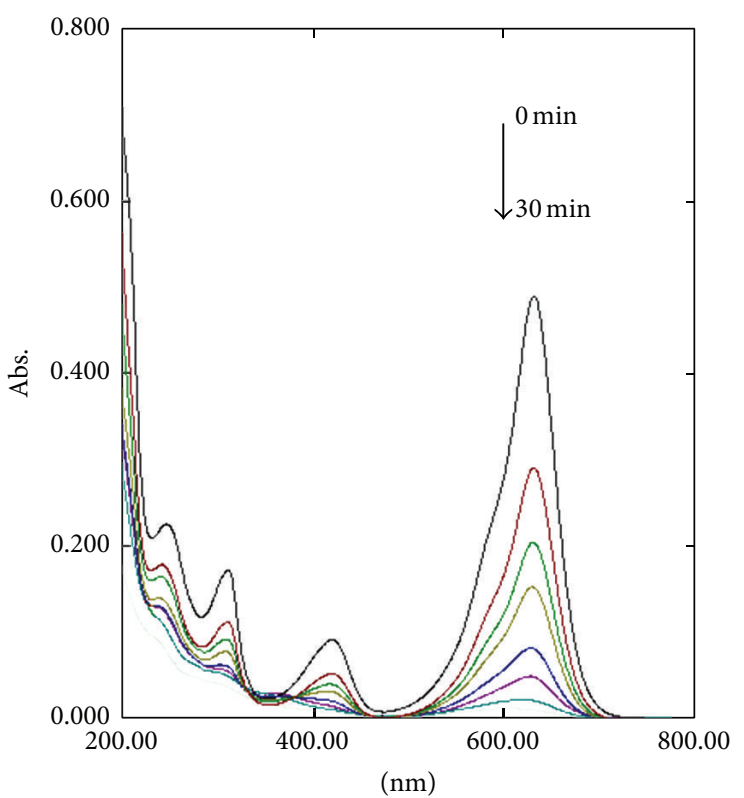

Figure 9: Evolution of UV-Vis spectra of Methyl Green (MG) aqueous solution with reaction time (initial concentration of $\mathrm{MG}=75 \mathrm{mg}$, photocatalyst amount $=0.75 \mathrm{~g}, \mathrm{HP}=8 \mathrm{~mL}$, and irradiation time $=30 \mathrm{~min}$ at $\mathrm{pH}=7$ ).

TABLE 3: COD measurements.

\begin{tabular}{lc}
\hline Sample & \% of COD reduction \\
\hline $\mathrm{TiO}_{2}(\mathrm{P} 25)$ & 47.94 \\
$\mathrm{TiO}_{2} / \mathrm{AC}$ & 98.80 \\
$\mathrm{TiO}_{2} / \mathrm{NC}$ & 95.11 \\
\hline
\end{tabular}

of photocatalyst, and $8 \mathrm{~mL}$ of $\mathrm{H}_{2} \mathrm{O}_{2}$. Solutions were then analyzed every 30 minutes. Figure 9 shows the evolution of the UV-Vis spectra. Four absorption peaks can be observed in the spectrum corresponding to the initial MG solution: the peak observed in the visible region at $631 \mathrm{~nm}$ is due to the green color of the chromophore of MG, and three other peaks at $420 \mathrm{~nm}, 315 \mathrm{~nm}$, and $256 \mathrm{~nm}$ correspond to the benzoic rings in the dye structure. Upon $30 \mathrm{~min}$ irradiation, in the presence of the $\mathrm{TiO}_{2} / \mathrm{AC}$ catalyst, the peak corresponding to the dye chromophore completely disappeared. COD analyses were performed to confirm the complete mineralization of MG. The percentage of COD elimination is presented in Table 3. After $60 \mathrm{~min}$ irradiation in the presence of $\mathrm{TiO}_{2} / \mathrm{AC}$ and $\mathrm{TiO}_{2} / \mathrm{NC}, 98.80 \%$ and $95.11 \%$ of $\mathrm{COD}$ elimination are obtained, respectively. These results confirmed that $\mathrm{TiO}_{2} / \mathrm{AC}$ are more efficient for MG degradation, as already observed from kinetic study (Figure 7).

3.8. Reusing of the Photocatalytic Materials. In order to study the reusability of the proposed photocatalysts, repeated degradation experiments were performed under optimized conditions. At the end of the degradation process, the suspension was centrifuged and the catalyst washed with water and dried at $120^{\circ} \mathrm{C}$ for future uses (Figure 10). The decrease in degradation efficiency is not significant for the supported 


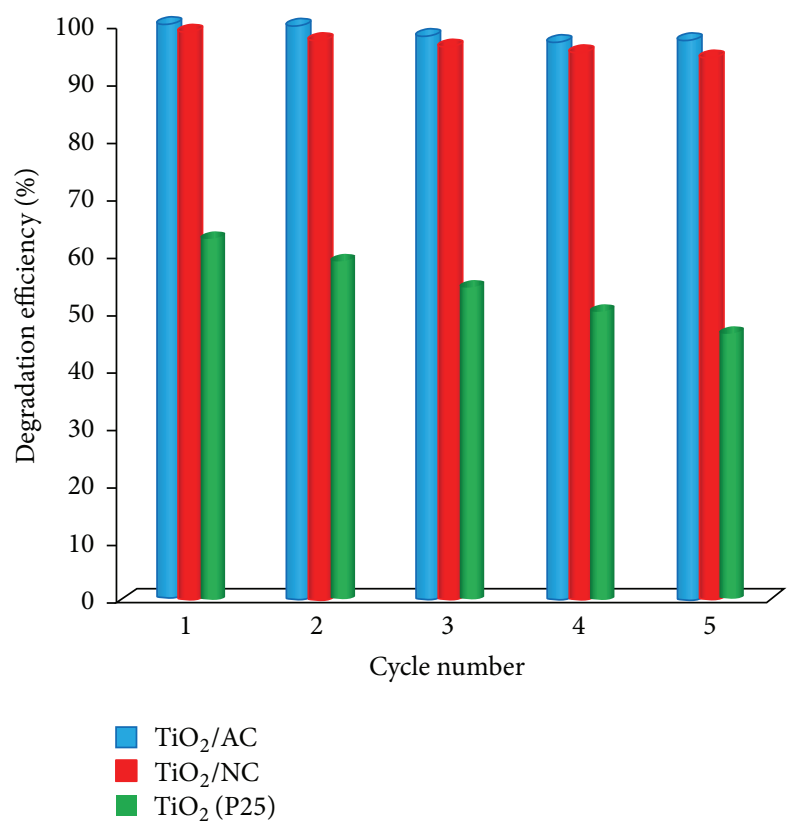

FIGURE 10: MG degradation by repeated use of the prepared photocatalysts (initial concentration of $M G=75 \mathrm{mg}$, photocatalyst amount $=0.75 \mathrm{~g}$, and irradiation time $=180 \mathrm{~min}$ ).

$\mathrm{TiO}_{2}$ materials, $\mathrm{TiO}_{2} / \mathrm{AC}$ and $\mathrm{TiO}_{2} / \mathrm{NC}$, whereas, for the nonsupported titania powder, $\mathrm{TiO}_{2}$ (P25), the decrease in activity is really noticeable. These results prove the positive effect of using a porous support for stabilizing $\mathrm{TiO}_{2}$ particles, resulting not only in higher photocatalytic activity but also in enhancing the stability of the proposed materials.

\section{Conclusions}

$\mathrm{TiO}_{2}$ nanoparticles were immobilized on the surface of two different supports, natural clay and activated carbon. The resulting photocatalysts $\mathrm{TiO}_{2} / \mathrm{AC}$ and $\mathrm{TiO}_{2} / \mathrm{NC}$ were characterized by means of XRD, SEM, TEM, and $\mathrm{N}_{2}$ physisorption. $\mathrm{TiO}_{2} / \mathrm{AC}$ was found to be more efficient towards UV-photocatalytic degradation of Methyl Green in aqueous solution than $\mathrm{TiO}_{2} / \mathrm{NC}$. This can be due to the particular physicochemical properties of the AC support together with increased light absorption related to its optical properties. Both $\mathrm{TiO}_{2}$ supported catalysts were considerably more efficient than the nonsupported $\mathrm{TiO}_{2}$ (P25) powder, pointing to a positive effect of $\mathrm{TiO}_{2}$ nanoparticle immobilization on both supports. Degradation was found to be slightly more efficient at high $\mathrm{pH}$. The optimum catalyst loading for efficient removal was found to be $0.75 \mathrm{~g} / \mathrm{L}$, for both supported catalysts. The evolution of UV-Vis spectra together with COD measurements confirmed the complete mineralization of the organic dye. After $60 \mathrm{~min}$ irradiation in the presence of $\mathrm{TiO}_{2} / \mathrm{AC}$ and $\mathrm{TiO}_{2} / \mathrm{NC}, 98.80 \%$ and $95.11 \%$ of $\mathrm{COD}$ elimination were, respectively, measured. Moreover, using $\mathrm{AC}$ and $\mathrm{NC}$ as supports for immobilizing $\mathrm{TiO}_{2}$ nanoparticles resulted in enhancement of the stability of the supported photocatalysts, in comparison to nonsupported $\mathrm{TiO}_{2}$ powders.

\section{Conflict of Interests}

The authors declare that there is no conflict of interests regarding the publication of this paper.

\section{References}

[1] J. E. B. McCallum, S. A. Madison, S. Alkan, R. L. Depinto, and R. U. R. Wahl, "Analytical studies on the oxidative degradation of the reactive textile dye Uniblue A," Environmental Science \& Technology, vol. 34, no. 24, pp. 5157-5164, 2000.

[2] P. A. Carneiro, R. F. P. Nogueira, and M. V. B. Zanoni, "Homogeneous photodegradation of C.I. Reactive Blue 4 using a photo-Fenton process under artificial and solar irradiation," Dyes and Pigments, vol. 74, no. 1, pp. 127-132, 2007.

[3] H. Bel Hadjltaief, P. Da Costa, M. E. Galvez, and M. Ben Zina, "Influence of operational parameters in the heterogeneous photo-fenton discoloration of wastewaters in the presence of an iron-pillared clay," Industrial \& Engineering Chemistry Research, vol. 52, no. 47, pp. 16656-16665, 2013.

[4] A. Nezamzadeh-Ejhieh and Z. Shams-Ghahfarokhi, "Photodegradation of methyl green by nickel-dimethylglyoxime/ZSM-5 zeolite as a heterogeneous catalyst," Journal of Chemistry, vol. 2013, Article ID 104093, 11 pages, 2013.

[5] T. Geethakrishnan and P. K. Palanisamy, "Degenerate four-wave mixing experiments in Methyl green dye-doped gelatin film," Optik, vol. 117, no. 6, pp. 282-286, 2006.

[6] U. I. Gaya and A. H. Abdullah, "Heterogeneous photocatalytic degradation of organic contaminants over titanium dioxide: a review of fundamentals, progress and problems," Journal of Photochemistry and Photobiology C: Photochemistry Reviews, vol. 9, no. 1, pp. 1-12, 2008.

[7] S. Ahmed, M. G. Rasul, R. Brown, and M. A. Hashib, "Influence of parameters on the heterogeneous photocatalytic degradation of pesticides and phenolic contaminants in wastewater: a short review," Journal of Environmental Management, vol. 92, no. 3, pp. 311-330, 2011.

[8] I. K. Konstantinou and T. A. Albanis, "TiO2-assisted photocatalytic degradation of azo dyes in aqueous solution: kinetic and mechanistic investigations: a review," Applied Catalysis B: Environmental, vol. 49, no. 1, pp. 1-14, 2004.

[9] J. Saien and A. R. Soleymani, "Feasibility of using a slurry falling film photo-reactor for individual and hybridized AOPs," Journal of Industrial and Engineering Chemistry, vol. 18, no. 5, pp. 16831688, 2012.

[10] A. Omri and M. Benzina, "Almond shell activated carbon: adsorbent and catalytic support in the phenol degradation," Environmental Monitoring and Assessment, vol. 186, no. 6, pp. 3875-3890, 2014.

[11] A. Panniello, M. L. Curri, D. Diso et al., "Nanocrystalline $\mathrm{TiO}_{2}$ based films onto fibers for photocatalytic degradation of organic dye in aqueous solution," Applied Catalysis B: Environmental, vol. 121-122, no. 13, pp. 190-197, 2014.

[12] F. Sayilkan, M. Asiltürk, Ş. Şener, S. Erdemoğlu, M. Erdemoğlu, and H. Sayilkan, "Hydrothermal synthesis, characterization and photocatalytic activity of nanosized $\mathrm{TiO}_{2}$ based catalysts for rhodamine B degradation," Turkish Journal of Chemistry, vol. 31, no. 2, pp. 211-221, 2007.

[13] D. Hao, Z. Yang, C. Jiang, and J. Zhang, "Photocatalytic activities of $\mathrm{TiO}_{2}$ coated on different semiconductive $\mathrm{SiC}$ foam supports," Journal of Materials Science \& Technology, vol. 29, no. 11, pp. 1074-1078, 2013. 
[14] S. N. Hosseini, S. M. Borghei, M. Vossoughi, and N. Taghavinia, "Immobilization of $\mathrm{TiO}_{2}$ on perlite granules for photocatalytic degradation of phenol," Applied Catalysis B: Environmental, vol. 74, no. 1-2, pp. 53-62, 2007.

[15] C. Li, B. Wang, H. Cui, J. Zhai, and Q. Li, "Preparation and characterization of buoyant nitrogen-doped $\mathrm{TiO}_{2}$ composites supported by fly ash cenospheres for photocatalytic applications," Journal of Materials Science and Technology, vol. 29, no. 9, pp. 835-840, 2013.

[16] K. K. Kalebaila and C. Fairbridge, "UV photocatalytic degradation of commercial naphthenic acid using $\mathrm{TiO}_{2}$-zeolite composites," Journal of Water Resource and Protection, vol. 6, no. 12, pp. 1198-1206, 2014.

[17] H. Bel Hadjltaief, M. E. Galvez, P. Da Costa, and M. Ben Zina, " $\mathrm{TiO}_{2}$ /clay as a heterogeneous catalyst in photocatalytic/photochemical oxidation of anionic reactive blue 19," Arabian Journal of Chemistry, 2014.

[18] Y. Ao, J. Xu, D. Fu, X. Shen, and C. Yuan, "Low temperature preparation of anatase $\mathrm{TiO}_{2}$-coated activated carbon," Colloids and Surfaces A: Physicochemical and Engineering Aspects, vol. 312, no. 2-3, pp. 125-130, 2008.

[19] A. Omri, M. Benzina, and F. Bennour, "Industrial application of photocatalysts prepared by hydrothermal and sol-gel methods," Journal of Industrial and Engineering Chemistry, vol. 21, pp. 356362, 2015.

[20] T. Torimoto, S. Ito, S. Kuwabata, and H. Yoneyama, "Effects of adsorbents used as supports for titanium dioxide loading on photocatalytic degradation of propyzamide," Environmental Science \& Technology, vol. 30, no. 4, pp. 1275-1281, 1996.

[21] H. Bel Hadjltaief, P. Da Costa, P. Beaunier, M. E. Gálvez, and M. Ben Zina, "Fe-clay-plate as a heterogeneous catalyst in photo-Fenton oxidation of phenol as probe molecule for water treatment," Applied Clay Science, vol. 91-92, pp. 46-54, 2014.

[22] A. Omri, A. Wali, and M. Benzina, "Adsorption of bentazon on activated carbon prepared from Lawsonia inermis wood: equilibrium, kinetic and thermodynamic studies," Arabian Journal of Chemistry, 2012.

[23] M. Benzina and A. Bellagi, "Détermination des propriétés $\mathrm{du}$ réseau poreux de matériau argileux par les techniques d'adsorption d'azote et de porosimétrie au mercure en vue de leur utilisation pour la récupération des gaz," Annales de Chimie, vol. 15 , no. 6, pp. 315-336, 1990.

[24] E. Hmani, S. Chaabane Elaoud, Y. Samet, and R. Abdelhédi, "Electrochemical degradation of waters containing O-Toluidine on $\mathrm{PbO}_{2}$ and BDD anodes," Journal of Hazardous Materials, vol. 170, no. 2-3, pp. 928-933, 2009.

[25] B. Braconnier, C. A. Páez, S. Lambert et al., "Ag- and $\mathrm{SiO}_{2}$-doped porous $\mathrm{TiO}_{2}$ with enhanced thermal stability," Microporous and Mesoporous Materials, vol. 122, no. 1-3, pp. 247-254, 2009.

[26] R. A. Spurr and H. Myers, "Quantitative analysis of anataserutile mixtures with an X-ray diffractometer," Analytical Chemistry, vol. 29, no. 5, pp. 760-762, 1957.

[27] Z. Ambrus, K. Mogyorósi, Á. Szalai et al., "Low temperature synthesis, characterization and substrate-dependent photocatalytic activity of nanocrystalline $\mathrm{TiO}_{2}$ with tailor-made rutile to anatase ratio," Applied Catalysis A: General, vol. 340, no. 2, pp. 153-161, 2008.

[28] I. Poulios and I. Tsachpinis, "Photodegradation of the textile dye Reactive Black 5 in the presence of semiconducting oxides," Journal of Chemical Technology \& Biotechnology, vol. 74, no. 4, pp. 349-357, 1999.
[29] A. Nezamzadeh-Ejhieh and M. Amiri, "CuO supported clinoptilolite towards solar photocatalytic degradation of p-aminophenol," Powder Technology, vol. 235, pp. 279-288, 2013.

[30] A. Khataee, M. Sheydaei, A. Hassani, M. Taseidifar, and S. Karaca, "Sonocatalytic removal of an organic dye using $\mathrm{TiO}_{2} /$ Montmorillonite nanocomposite," Ultrasonics Sonochemistry, vol. 22, no. 1, pp. 404-411, 2015.

[31] B. Krishnakumar, K. Selvam, R. Velmurugan, and M. Swaminathan, "Influence of operational parameters on photodegradation of Acid Black 1 with ZnO," Desalination and Water Treatment, vol. 24, no. 1-3, pp. 132-139, 2010.

[32] D. Rajamanickam and M. Shanthi, "Photocatalytic degradation of an azo dye Sunset Yellow under UV-A light using $\mathrm{TiO}_{2} / \mathrm{CAC}$ composite catalysts," Spectrochimica Acta Part A: Molecular and Biomolecular Spectroscopy, vol. 128, no. 15, pp. 100-108, 2014.

[33] N. San, A. Hatipoğlu, G. Koçtürk, and Z. Çinar, "Prediction of primary intermediates and the photodegradation kinetics of 3-aminophenol in aqueous $\mathrm{TiO}_{2}$ suspensions," Journal of Photochemistry and Photobiology A: Chemistry, vol. 139, no. 2-3, pp. 225-232, 2001. 

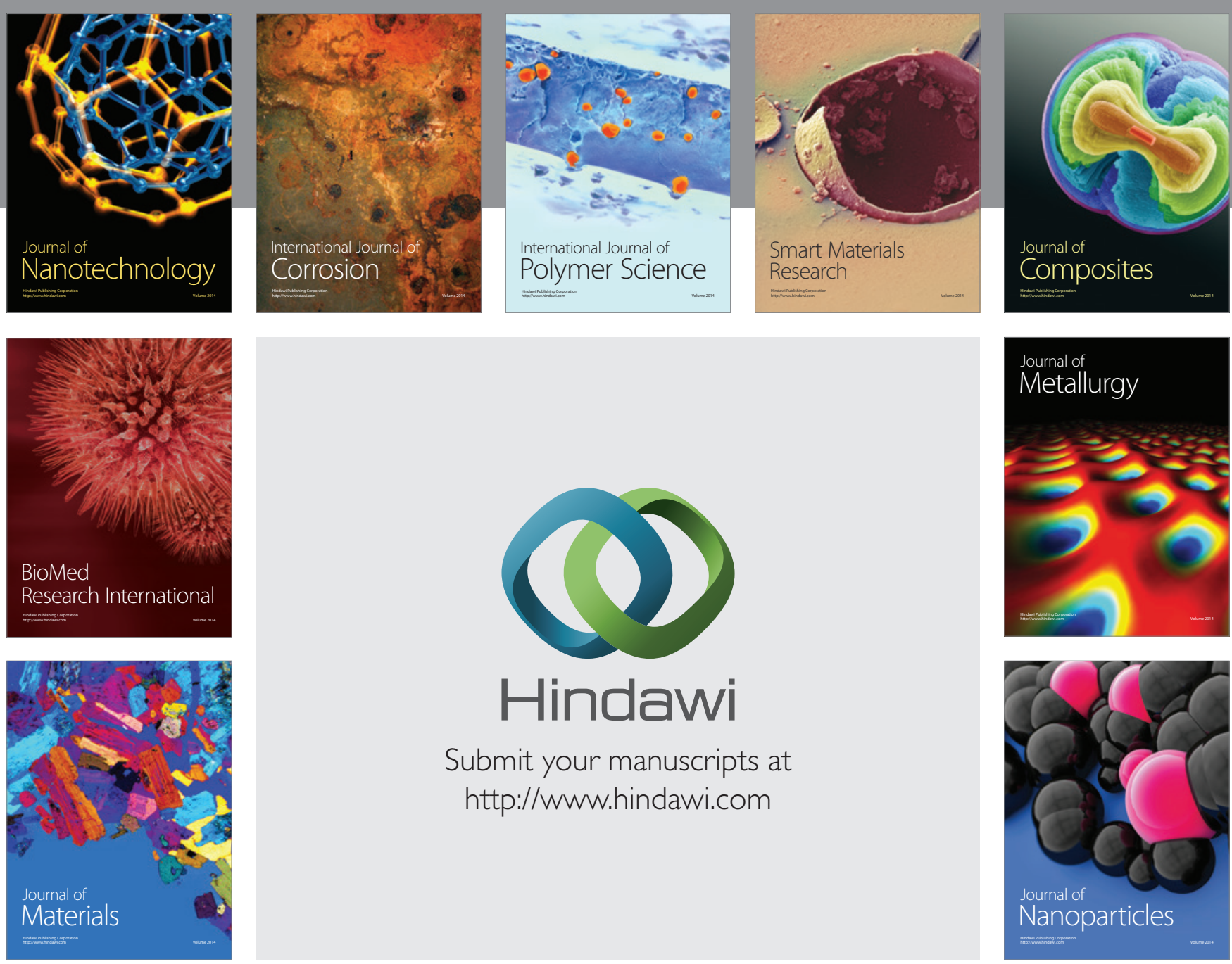

Submit your manuscripts at http://www.hindawi.com
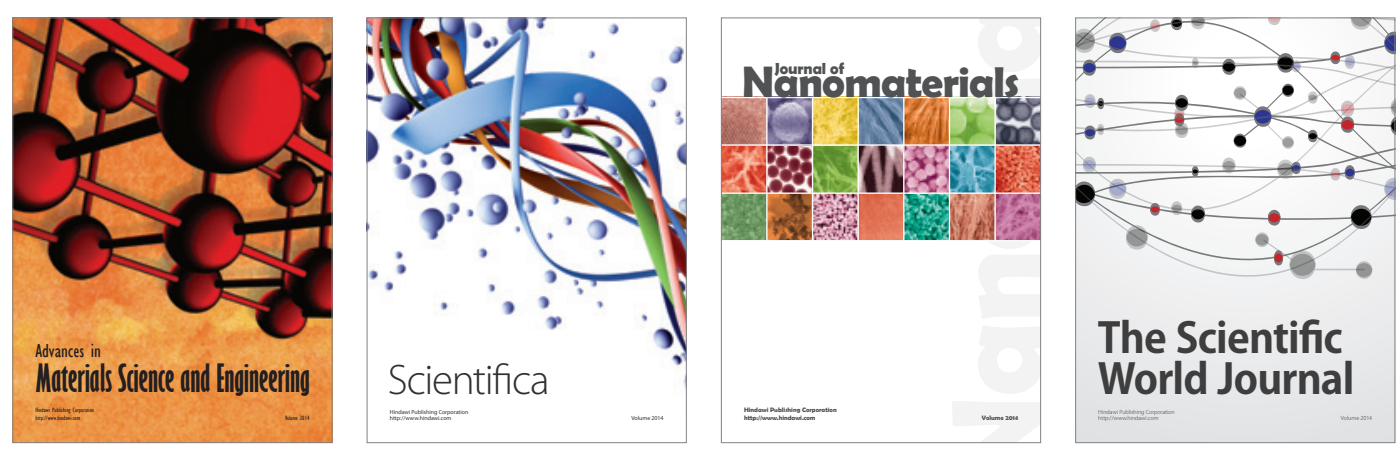

\section{The Scientific World Journal}
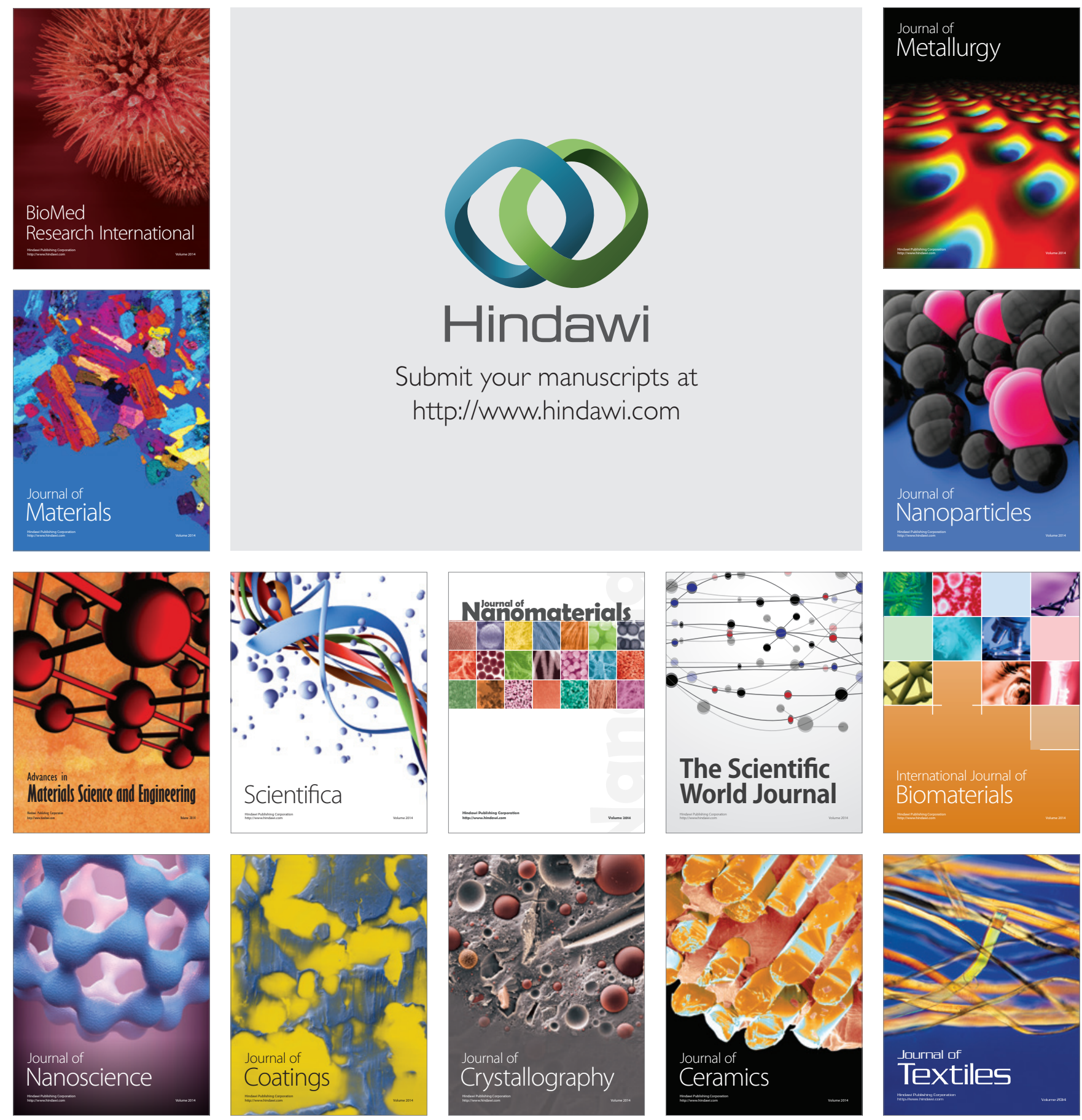